\title{
Revista de Educação (1921-1923): moral e civilidade republicanas na formação docente
}

\author{
Carlos da Fonseca Brandão \\ Departamento de Educação da UNESP - Assis e Programa de Pós-graduação em Educação da UNESP - Marília, \\ SP-Brasil. \\ cbrandao@assis.unesp.br \\ Angélica Pall Oriani \\ Faculdade de Filosofia e Ciências da UNESP - Marília, São Paulo-Brasil \\ angelicaoriani@hotmail.com \\ Leila Maria Inoue \\ Faculdade de Filosofia e Ciências da UNESP - Marília, São Paulo-Brasil \\ leilinoue@yahoo.com.br
}

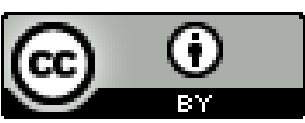

EDUCAÇÃO: Teoria e Prática, Rio Claro, SP, Brasil - eISSN: 1981-8106

Está licenciada sob Licença Creative Common

\section{Resumo}

Neste texto, problematizam-se os conteúdos de moral e civismo divulgados em cinco artigos da Revista de Educação, periódico de destinação pedagógica, publicado pela antiga Escola Normal de Piracicaba, em Piracicaba-SP, entre 1921 e 1923 e que teve Lourenço Filho como um dos seus editores. Para a análise, foram utilizados aspectos da teoria dos processos de civilização, com base na ideia de controle das emoções, proposta pelo sociólogo alemão Norbert Elias, nas primeiras décadas do século XX. Por meio de abordagem histórica, constataram-se nesses artigos os princípios de civilidade e de moralidade que deveriam ser ensinados por meio da escola aos normalistas para que esses os ensinassem aos seus alunos, futuros cidadãos da República. A partir da análise dos artigos desse periódico foi possível constatar o desenho de cidadão que se divulgava e, em decorrência, a disseminação - por meio da escola - de valores relativos às condutas sociais que condiziam com os padrões de comportamento de indivíduos civilizados para a República Brasileira.

Palavras-chave: Revista de Educação. Moral e civilidade. Norbert Elias.

\section{Revista de Educação (1921-1923): republican moral and civility in teacher training}

\footnotetext{
Abstract

In this paper, are analyzed the content of morality and civility disclosed in five articles published in the Revista de Educação, educational periodic published by the School for Teaching Training of Piracicaba, between 1921 and 1923, and that had Lourenço Filho as editor. For the analysis, it was used aspects of the theory of civilization processes, based on
} 
the emotional control idea, proposed by the German sociologist Norbert Elias, in the first decades of the twentieth century. Through historical approach, it was founded in these articles the principles of civility and of morality that should be taught through the school to the teaching training students so they could teach it to their students, future citizens of Republic. From the analysis of the articles of this journal it was possible to observe the "drawing" of citizen who was disclosed and, consequently, the spread - through the school of values related to social behavior that matched to the standards of civilized individuals to the Brazilian Republic.

Keywords: Revista de Educação. Morality and civility. Norbert Elias.

\section{Revista de Educación (1921-1923): moral y civilidad republicanas en la formación docente}

\section{Resumen}

En este texto, se problematizan los contenidos de moral y civismo divulgados en cinco artículos de la Revista de Educación, periódico con fines pedagógicos, publicado por la antigua Escola Normal de Piracicaba, en Piracicaba-SP, entre 1921 y 1923 y que tuvo a Lourenço Filho como uno de sus editores. Para el análisis, se utilizaron aspectos de la teoría de los procesos de civilización, con base en la idea de control de las emociones, propuesta por el sociólogo alemán Norbert Elias, en las primeras décadas del siglo XX. Por medio del abordaje histórico, se constataron en esos artículos los principios de civilidad y de moralidad que deberían enseñarse por medio de la escuela a los normalistas, para que estos los enseñaran a sus alumnos, futuros ciudadanos de la República. A partir del análisis de los artículos de este periódico fue posible constatar el diseño de ciudadano que se divulgaba y, en consecuencia, la diseminación - por medio de la escuela - de valores relativos a las conductas sociales que condecían con los patrones de comportamiento de individuos civilizados para la República Brasileña.

Palabras clave: Revista de Educación. Moral y civilidad. Norbert Elias

\section{Introdução}

O objetivo deste texto é analisar cinco artigos publicados pela Revista de Educação, periódico editado pela Escola Normal de Piracicaba, entre os anos de 1921 e 1923, buscando identificar os conteúdos de moral e civismo veiculados nos artigos desse periódico com a ideia de controle das emoções presente na teoria dos processos de civilização do sociólogo alemão Norbert Elias. Partindo de uma abordagem histórica, e focando nas questões de moral e civismo, encontramos nesses artigos os princípios que deveriam ser ensinados aos normalistas para que os ensinassem aos seus alunos, futuros cidadãos da República.

Ao realizar a presente pesquisa, observamos que naquele período (1921-1923) havia uma circulação mais intensa do discurso a respeito da importância dos saberes sobre a 
moral e o civismo na formação de cidadãos - por meio da escola - para a construção e consolidação da nação brasileira republicana ${ }^{1}$. Por outro lado, a questão do controle das emoções, central na teoria dos processos de civilização de Elias, influencia não só a conduta individual, mas, também (e em igual medida), a conduta social dos indivíduos. Assim, a escola, ao transmitir, entre outros, princípios de moral e civismo, está atuando sobre o indivíduo, no sentido de aumentar o patamar de controle de suas emoções individuais para que esse mesmo indivíduo adquira um determinado padrão de comportamento, minimamente adequado para o convívio em uma sociedade pacificada (BRANDÃO, 2007; ELIAS, 1993).

Delimitamos a temática de nossa análise à divulgação dos princípios de moral e ao civismo, presentes nos artigos publicados na Revista de Educação, por considerarmos que com essa temática podemos compreender melhor a ideia eliasiana de que a conduta social influencia (e, de certa maneira, regula) a conduta individual, bem como o seu inverso, ou seja, a ideia de que a conduta individual também influencia as condutas sociais dos indivíduos.

\section{$2 \quad$ A Revista de Educação}

A Revista de Educação é um periódico de destinação pedagógica, criado pela antiga Escola Normal de Piracicaba, logo após a implantação da Reforma da Instrução Pública de 1920, conhecida como Reforma Sampaio Dória, então Diretor Geral da Instrução Pública do Estado de São Paulo. No volume I, no 2, publicado em setembro de 1922, a revista traz em sua contracapa a finalidade com que veio a lume:

\footnotetext{
A Revista de Educação, orgam² da Escola Normal de Piracicaba e escolas annexas, conforme a sua própria denominação indica, é uma publicação periódica que tem por fim estudar, discutir e divulgar as mais salientes questões que, directa ou indirectamente, se prendem á educação em geral. O objectivo immediato é o de contribuir de uma maneira pratica e tão efficaz quanto possível, para o progresso scientifico do ensino primário e secundário; e, como, nesse ensino o mal mais geral e nefasto é o verbalismo estéril, o aprendizado só de palavras, o cultivo desintelligente e brutal da memória, a "Revista" inscreve como primeiro artigo de seu programma o combate systematico a esse desvio de instruç̧ão, que tanto mal
}

\footnotetext{
${ }^{1}$ Apesar de nossa análise ter como objeto os artigos da Revista de Educação, publicada em um período curto de três anos, as ideias de formação da nacionalidade brasileira, por meio de saberes de moral e civismo, circularam, segundo alguns pesquisadores, por um período relativamente longo, desde a Independência do Brasil, em 1822 (NAGLE, 1974; DE LUCA, 1999).

${ }^{2}$ Quando da citação de trechos do periódico, mantivemos a ortografia original.
} 
causa á formação do espírito da creança, e do adolescente. Por isso mesmo, toda collaboração, ao mesmo tempo que orientada nesse sentido, deve ser vasada nos moldes da concisão, da clareza e da precisão da linguagem, fazendo questão das ideas e não só das palavras.

Pela apresentação é possível observar que os objetivos do periódico seriam combater o ensino verbalista de mera memorização e contribuir para a formação do professorado, ampliando o debate sobre questões educacionais do país e, também, apoiando o reformador Sampaio Dória, que defendia a moral e o civismo como principais elementos na formação da nova sociedade republicana ${ }^{3}$.

Foi em um momento de intensas manifestações de cunho nacionalista, efervescência cultural, política e social, haja vista os vários acontecimentos que marcaram o momento histórico - como a Primeira Guerra Mundial, a Semana de Arte Moderna e o Centenário da Independência do Brasil - que a Revista de Educação foi publicada ${ }^{4}$. As ideias de efervescência educacional e otimismo pedagógico ${ }^{5}$, que tomaram a Primeira República, podem justificar as publicações sobre a educação e a cultura, entre outros temas que buscaram valorizar os elementos nacionais.

Com a Proclamação da República, iniciou-se um movimento de superação do período Imperial considerado atrasado em todos os níveis. A escolarização passou a ser vista como o principal meio para a formação do cidadão republicano brasileiro e para fixar o imigrante estrangeiro no país que o acolheu. Em decorrência, a valorização dos elementos nacionais pela educação e pela escola se tornou um ponto importante para a formação da nação naquele momento e, com isso, foi dada maior ênfase na formação de professores.

Segundo Hilsdorf (1998), uma das primeiras medidas de Sampaio Dória, ao assumir o cargo de Diretor Geral, foi distribuir em diversas escolas do Estado pessoas de sua confiança,

\footnotetext{
${ }^{3}$ De acordo com Carvalho (2010, p. 118), Sampaio Dória "[...] é o doutrinador e o propagandista da extinção do analfabetismo que faz uma opção política pela escola alfabetizante de dois anos, ele é também o educador spencerianamente atento aos meios e aos métodos pedagógicos de cultivo ao físico, da inteligência e do caráter da criança convencido de que esse era o caminho para deslanchar o desenvolvimento natural de suas faculdades. Desenvolvimento esse que, pela lei da recapitulação abreviada, que [...] era peça nuclear do credo pedagógico de Dória, seria necessariamente homólogo do desenvolvimento da civilização. Por isso, o reformador que propõe a escola de dois anos como uma fórmula mágica de extinção do analfabetismo é o pedagogo que acredita conhecer um método de ensino capaz de promover, com dois anos de escolarização, a cultura das faculdades intelectuais, morais e físicas da criança, dotando-a dos meios e das condições necessárias para seu natural posterior aperfeiçoamento: o método da intuição analítica".

${ }^{4}$ O professor Lourenço Filho foi um dos principais criadores e editores da Revista de Educação, ex-aluno e colaborador de Sampaio Dória, por isso, há indícios de que a revista foi criada com estratégia editorial para divulgar a Reforma de 1920, e assim, de certa maneira, legitimá-la.

${ }^{5}$ Expressões utilizadas, entre outros, por Nagle (1974).
} 
que propagariam as medidas implantadas pela Reforma de 1920, garantindo sua efetivação. Nesse sentido, a vinda de Lourenço Filho para lecionar Psicologia e Pedagogia na Escola Normal de Piracicaba tinha o intuito de fazer a campanha em prol da Reforma Sampaio Dória naquela região. Hilsdorf afirma, ainda, que a vinda de Lourenço Filho

para Piracicaba não foi um ato do tipo "remoção de cadeira", tão comum na vida dos professores: ela está diretamente ligada à implantação da reforma do sistema público paulista empreendida por Antonio Sampaio Dória em fins de 1920 $[\ldots]$.

Para dar conta desse radical programa, Sampaio Dória colocou em pontos chaves, administrativos e pedagógicos, da organização paulista de ensino, nomes do universo escolar compromissados com ele, quer do ponto de vista do partilhamento das idéias, quer do ponto de vista das relações pessoais, professores jovens, muitos deles ex-alunos, adeptos das novas teorias do ensino e simpatizantes ou membros, como ele, da Liga Nacionalista - que objetivava a nacionalização do país e a desalfabetização (HILSDORF, 1998, p. 96-98).

Consideramos, portanto, que a Revista de Educação foi criada como estratégia editorial para fazer a propaganda da Reforma Sampaio Dória, contribuindo para sua efetivação. Mas, é importante notar que quando o volume I, no. 1 foi publicado, Dória já não estava mais à frente da Direção Geral da Instrução Pública Paulista. Mesmo com isso, ele não deixou de influenciar as publicações da Revista e as discussões sobre a instrução no cenário educacional paulista depois de sua exoneração.

Com relação ao período de publicação da Revista da Educação (1921-1923), há que se ressaltar a sua brevidade. Assim, foram encontrados 6 números, divididos em 3 volumes e todos publicados pela tipografia do Jornal de Piracicaba (diário que, atualmente, é publicado na cidade). 0 volume 1 é composto por dois números; o volume 2 por três números e o volume 3 é composto por apenas um único número, o que indica a decadência da Revista naquele momento. Em seu curto período de existência ${ }^{6}$, a Revista teve 7 editores, a saber: Honorato Faustino (diretor da Escola Normal de Piracicaba e anexas), Antônio Pinto de Almeida Ferraz e Lourenço Filho (professores da Escola Normal de Piracicaba), Pedro Crem, Dário Brasil, Antônio dos Santos Veiga e Maria Graner (professores da Escola Modelo uma das anexas à Escola Normal de Piracicaba). Os autores eram professores da própria escola e anexas, de outras Escolas Normais do Estado de São Paulo, como Campinas, Pirassununga e Casa Branca, bem como alunos e outros profissionais, como, por exemplo, médicos.

\footnotetext{
${ }^{6} \mathrm{~A}$ ida de Lourenço Filho (maior idealizador da Revista) para reformar a Instrução Pública no Ceará, em 1922, pode ter contribuído para a extinção desse periódico.
} 
Nery (2009, p. 121) levanta a hipótese de que a nomeação de Lourenço Filho representou uma tentativa de reequilibrar as forças, desestabilizando a hegemonia do grupo de professores organizados em torno da Revista da Escola Normal de São Carlos (19161923). Como mencionamos acima, para garantir com êxito a aceitação da Reforma, Sampaio Dória promoveu uma série de trocas no corpo docente das instituições. De acordo com Nery, Dória fez uma reorganização, transferindo os professores da Escola Normal Secundária de São Carlos para as antigas Escolas Normais Primárias.

Dessa forma, há igualmente indícios de que a Revista de Educação objetivava desarticular a Revista da Escola Normal de São Carlos, cujos colaboradores apoiavam o exdiretor Oscar Thompson.

Os possíveis leitores da Revista de Educação seriam os estudantes das escolas normais, os professores já formados e outros profissionais que trabalhavam na área de educação. O periódico publicou artigos sobre diversas temáticas que estão relacionadas ao contexto político, econômico, cultural, social e, principalmente educacional, vivido no Estado de São Paulo, nas primeiras décadas do século $X X$, relativas às tentativas de modernização do ensino e extinção do analfabetismo, buscando formar uma sociedade nova. Alguns temas concernem às disciplinas da Escola Normal, dirigidas especialmente para a formação dos normalistas, como Prática Pedagógica, Higiene, História, Música etc., além de auxiliar no trabalho dos professores que já atuavam na escola primária ${ }^{7}$.

\section{A moral e o civismo nos artigos da Revista de Educação}

Nesse contexto da Educação Brasileira, os conteúdos sobre Moral e Civismo eram considerados essenciais para a formação do novo cidadão republicano e para a integração dos imigrantes estrangeiros. O primeiro dos artigos foi escrito por Thales Castanho de Andrade $^{8}$ e tinha como título Do ensino de história (1921). Dario Brasil ${ }^{9}$ escreveu O civismo

\footnotetext{
${ }^{7}$ Além de publicar sobre temas nacionalistas, a Revista se destacou pela publicação do artigo Estudo da Atenção Escola (v. I, n. 2, 1921), de Lourenço Filho. Nesse artigo, o autor explicita que o conhecimento do funcionamento da mente infantil pode ajudar o trabalho do professor. Fator importante para o ensino, despertar e manter a atenção da criança é tema central do artigo.

${ }^{8}$ Thales Castanho de Andrade era formado pela Escola Normal de Piracicaba e amigo de Lourenço Filho desde 1915, quando juntos lecionaram com Sud Mennucci no Grupo Escolar de Porto Ferreira.

${ }^{9}$ Lente de Geografia e História na Escola Complementar de Piracicaba.
} 
pelo ensino de história, publicado no mesmo ano. No ano seguinte (1922), Pedro de Mello ${ }^{10}$ escreveu 7 de setembro de 1922, Sud Mennucci ${ }^{11}$ escreveu Um jubileu e, por fim, Joaquim da Silva ${ }^{12}$ escreveu Discurso.

De modo geral, esses artigos tratam da importância e da necessidade dos conhecimentos sobre a história pátria para o professor e para o cidadão, e ressaltam a importância do papel do professor na formação da sociedade e a educação como meio de impulsionar o desenvolvimento do país; os sentimentos patrióticos e os valores morais necessários aos cidadãos. Os artigos - Um Jubileu e Discurso - são discursos pronunciados aos normalistas, colocando o professor como exemplo de cidadão a ser seguido pela população.

Na opinião de Bittencourt (2008, p. 109), a História era entendida como componente da formação nacional, sem perder seu caráter universal. Parte dos intelectuais engajados nos projetos de modernização do país, pela via da industrialização, considerava a história da pátria - ao lado da geografia - disciplinas fundamentais que deviam ser disseminadas para o conjunto da população estudantil.

Com o estabelecimento do regime republicano, a Instrução Moral e Cívica substituiu as aulas de ensino religioso. A introdução dessas disciplinas nas escolas representou, por vezes, um apêndice da História ou, outras vezes, um acréscimo a essa disciplina, servindo para desenvolver o sentimento patriótico, direcionando a moral secular (BITTENCOURT, 2008 p. 117). Na opinião de De Luca (1999, p. 86-87):

Da história, por sua vez, esperava-se um conjunto coerente de tradições a serem partilhadas por todos. Acreditando-se conduzidos pela mão firme da metodologia científica, os historiadores debruçaram-se sobre o passado, privilegiando certos indivíduos e episódios de um trabalho de consagração que respondia às necessidades do momento. Emergiu então a figura do bandeirante, dilatador incansável das fronteiras. A narração da conquista e da manutenção do território foi transformada na grande epopéia nacional, redimindo não apenas o nosso passado, mas também as regiões tropicais que - afinal - dava sinais de poder conviver com a civilização. Essa construção excludente, que transpunha a recente supremacia desfrutada por São Paulo para o tempo mítico das origens, mal conseguia disfarçar suas implicações políticas.

\footnotetext{
${ }^{10}$ Lente de Francês na Escola Normal de Piracicaba.

${ }^{11}$ Delegado Regional de Ensino da Região de Piracicaba, no período em que Sampaio Dória foi Diretor da Instrução Pública de São Paulo. Escrevia para o jornal O Estado de S. Paulo sobre questões culturais, escolares e literárias, quando, em 1920, a convite de Sampaio Dória, comandou o recenseamento escolar em São Paulo, proposto pela Reforma Sampaio Dória. Em seguida, assumiu a chefia da Delegacia Regional de Ensino de Campinas e depois transferido para Piracicaba (HILSDORF, 1998).

${ }^{12}$ Lente de Psicologia da Escola Normal de Pirassununga.
} 
No artigo publicado em 1921, Andrade considerava que as lições de história deveriam ser ministradas da seguinte forma:

Quando uma creança tiver iniciada a sua educação escolar já pode e deve ir recebendo, também, os ensinamentos da historia. Não serão, por certo, lições que versem sobre os povos orientais ou cousa semelhante; serão por exemplo, noções históricas sobre a cidade em que o alumno residir, e depois, a pouco a pouco, sobre a ida do seu Estado, do seu paiz... Mais tarde, bem mais tarde, quando o educando já possuir solidas noções do tempo, largas noções sobre a terra, profundo sentimento de sua nacionalidade, eis chegado o instante propicio para saber com proveito a ida de todas as gentes, por toda a parte, em todos os tempos (ANDRADE, 1921, p. 48).

Já no artigo O Civismo pelo Ensino de História (v. I, no 1, 1921), Dario Brasil ressalta que o estudo da História Pátria despertou interesse diante da ação que a Liga Nacionalista vinha desenvolvendo contra o analfabetismo e a nova direção dada à Educação Cívica nas escolas brasileiras. Era preciso, além do conhecimento sobre História antiga, média e moderna, o conhecimento da História do Brasil e dos Estados. De acordo com Brasil (1921), a falta dos conhecimentos sobre o país dificultava a concretização dos fenômenos que modificam a sociedade e o próprio país. $\mathrm{O}$ autor critica a dissociação entre as disciplinas de História Pátria e Educação Cívica, já que não se pode conceber uma disciplina sem o discurso da outra:

A Historia é a base sobre que se fundamenta a Educação Cívica, que deve ser diffundida por meio de exemplos, conferencias, prelecç̧ões e artigos, por todo o paiz e principalmente pela pratica, como se faz nos Estados Unidos, na Itália, Allemanha e outros paizes europeus onde, as grandes em culto de homenagem cívica, aos túmulos dos grandes patriotas, são comuns (BRASIL, 1921, p. 23).

O autor considera que as disciplinas, realizadas da maneira mencionada acima, podem despertar o "amor do passado e o sentimento pátrio, e assim os indivíduos se tornam verdadeiros cidadãos" capazes de compreender seus direitos e deveres e desempenhar atitudes que interessam ao público e à coletividade. Para Brasil (1921, p. 24), os intelectuais precisam divulgar o patriotismo em benefício das massas.

$\mathrm{O}$ artigo 7 de Setembro (v. II, no 2, 1922), escrito por Pedro de Mello, é dedicado ao Centenário da Independência do Brasil e à importância da comemoração dessa data, para o país. Ao lado dos comentários do autor sobre a comemoração histórica dessa data, o artigo apresenta um hino intitulado Hymno do Ypiranga, escrito pelo próprio Mello. Ele ressalta que o Estado de São Paulo foi o cenário onde se desenrolou esse acontecimento de extrema importância para a nação. 
Ao raiar deste dia a alma nacional, de sul a norte, num grande frêmito de enthusiasmo, como uma harpa gigantesca, vibrou do intenso jubilo, porque elle rememorava a grande data nacional, a grande data secular, a mais gloriosa da nossa historia, pois que representa aquella em que se constituiu como nação autônoma e independente, a grande pátria brasileira (MELLO, 1922, p. 111).

Segundo De Luca (1999, p. 22), o ano de 1922 é carregado de dramaticidade e peso simbólico, pois, além do ano do Centenário da Independência, foi o ano da fundação do Partido Comunista e do Centro Dom Vital, de orientação católica, da Semana da Arte Moderna e do episódio do Forte de Copacabana, marco inicial do tenentismo. Sendo assim, estabeleceu-se uma associação entre o ano de 1922 e a ideia de novo.

O artigo Um Jubileu (v. II, no 1, 1922), por sua vez, é um discurso de Sud Mennucci pronunciado na comemoração do 250 aniversário da Escola Normal de Piracicaba. Em sua fala, Mennucci enfatiza a importância da Escola Normal e da instrução desenvolvida nessa instituição para o progresso do Estado; parabeniza o Dr. Honorato Faustino pela administração da escola, os mestres e os normalistas, futuros professores que formariam as novas gerações. Mennucci atribui ao trabalho docente o estatuto de uma função cívica.

É que esta festa é em si mesma uma glorificação: a exaltação de esforço pertinaz, da paciencia reflectida, da vontade disciplinada; é a glorificação de um trabalho exhaustivo e extenuante de gabinete, todo elle feito sem alarde, sem espalhafatos, e sem reclames; é emfim, a glorificação dos heroísmos obscuros que, no silencio das salas, forjam as bases impereciveis em que se esteiam a cultura e a civilização (MENNUCCI, 1922, p. 22).

Já o artigo intitulado Discurso (v. II, no 3, 1922) é de autoria de Joaquim da Silva, Lente de Psicologia da Escola Normal de Pirassununga. O artigo foi dirigido aos formandos da Escola Normal, relatando a importância da profissão docente e de seu dever em formar os brasileiros. Assim se expressa Silva:

Nosso paiz é uma terra de imigração. Ocioso seria demonstrar-vos que assimilar o imigrante é necessidade de vital importancia para a integridade da Patria.

Esta obra só a escola a pode realizar. As crianças, disse-o um educador americano, são a cadeia que ligará os homens entre si. Conquiste a criança uma vez sendo Ella ganha para o paiz, a família terá mais fortes laços que a prendam á terra que será sua pátria de adopção.

E não só o filho do extrangeiro se orientará assim o ensino. A escola nacionalista affirmará sua constante preoccupação de exaltar a nossa grandeza, as nossas possibilidades, o nosso valor (SILVA, 1922, p. 157).

Desse modo, a educação acompanhada dos saberes de moral e civismo seria a forma mais eficaz de construir a sociedade brasileira republicana. O escotismo, por exemplo, 
além de atividade física, era compreendido como uma escola de moral e civismo. Na Escola Normal de Piracicaba, a prática do escotismo também tinha o propósito de preparar os futuros professores para atuarem como instrutores de escoteiros na Escola Primária. Assim, o aluno da Escola Normal acompanhava o desenvolvimento das atividades escoteiras com os alunos da Escola Modelo anexa.

Mediante nossa análise, consideramos que a Revista de Educação (1921-1923) contribuiu para a divulgação dos saberes de moral e civismo. Os artigos selecionados e analisados representavam um conjunto de saberes que os professores da Escola Normal publicavam, junto de uma linha editorial que reconhecia sua importância para a formação do professor, naquele momento. Como a valorização dos elementos nacionais era imprescindível na formação dos cidadãos e da sociedade republicana da época, a divulgação desses conteúdos foi intensa. Observamos, portanto, a articulação entre o conteúdo dos artigos que compõem a revista com os princípios republicanos sobre escola, moral e civismo, divulgados em muitas instituições escolares naquele momento histórico.

\section{$4 \quad$ Alguns conceitos eliasianos e a Revista de Educação}

Em seu livro mais conhecido, $O$ processo civilizador, Elias problematiza as formas a partir das quais o homem se tornou civilizado e aprendeu a ter condutas que, ao longo da história, Ihe conferiram comportamentos sociais baseados na cortesia e gentileza. $O$ problema de que Elias parte é: quais foram as causas e como ocorreram as mudanças comportamentais que nos permitem considerar uma sociedade civilizada e outra bárbara em termos de costume e condutas sociais.

Buscando responder a esse questionamento, Elias recorre aos conceitos de Max Weber acerca da formação e estrutura do Estado, especialmente aos conceitos de monopólio do uso legítimo da força física e de monopólio da tributação, para argumentar que a criação dos Estados nacionais europeus, na Idade Média, e a consequente pacificação seguida, posteriormente, do surgimento dos primeiros núcleos urbanos (as cidades), proporcionou uma nova configuração social. Tanto quanto essas novas configurações sociais, os indivíduos também passaram a ter um novo padrão de comportamento, em função das 
alterações de suas estruturas mentais. É desse novo padrão de comportamento que surgem novas maneiras (regras) de regular suas condutas ${ }^{13}$.

Se antes a convivência social era regida por princípios ligados à força física, isto é, aqueles que dispunham de maior força física impunham a sua vontade aos mais fracos, a partir do momento em que os Estados nacionais europeus foram se configurando em Estados unificados, detentores do monopólio do uso legítimo da força física e também do monopólio da tributação, as relações sociais entre indivíduos de uma mesma sociedade (ou de um mesmo Estado) foram modificadas, assim como também foram modificadas as condutas individuais desses mesmos indivíduos, sempre numa mesma direção, quer seja, sempre aumentando o patamar de controle social e individual (autocontrole) ${ }^{14}$. Sintetizando, Elias (1994, p. 17) afirma que as "ligações entre mudanças na estrutura psíquica da sociedade e mudanças na estrutura do comportamento e da constituição psíquica" são intrínsecas e diretamente relacionadas, sempre numa via de mão dupla. Nesse sentido, conforme afirma Brandão (2007, p. 103):

À medida que as pessoas são obrigadas a viver pacificamente em sociedade, elas passam a observar as outras pessoas e a serem observadas (o que Elias chama de controle social), fazendo com que o seu código de conduta, ou padrão de comportamento, seja lentamente transformado, aumentando a compulsão de policiar o próprio comportamento.

Por esse motivo, de acordo com Elias, o controle explícito de pulsões e do comportamento decorreu desse movimento de constituição e consolidação de unidades sociais pacíficas. Desse modo, sentimentos antes não despertados, como a vergonha, o asco, a delicadeza e a polidez tornaram-se balizadores de condutas individuais consideradas civilizadas, as quais, por consequência, serviriam como referência para despertar no restante da sociedade a necessidade de se tornar mais civilizada.

De acordo com Elias, a internalização do autocontrole foi um processo crescente, fazendo com que, progressivamente, ações conscientes fossem transformadas em ações puramente inconscientes, mas de uma forma ou de outra, a "direção dessa transformação de conduta, sob a forma de regulação crescentemente diferenciada de impulsos, era determinada pela direção do processo de diferenciação social, pela progressiva divisão de

\footnotetext{
${ }^{13}$ À esses processos Elias dá os nomes de sociogênese e psicogênese, respectivamente. (ELIAS, 1993 e 1994)

${ }^{14}$ Quando Elias afirma que as alterações na estrutura mental individual (psicogênese) e as modificações nas relações sociais (sociogênese) ocorrem sempre numa mesma direção, ele não está afirmando que essas mudanças são previsíveis, inexoráveis ou pré-determinadas. Elias está afirmando que, analisadas a posteriori, é possível identificarmos a direção em que essas alterações ocorreram (ELIAS, 1993; BRANDÃO, 2007).
} 
funções e pelo crescimento das cadeias de interdependência", dentro das quais, "direta ou indiretamente, cada impulso, cada ação do indivíduo tornavam-se integrados". Elias considera, ainda, que a fixação do autocontrole mental como traço de personalidade característico do ser humano dá-se em função de diversos elementos, entre os quais citamos a "monopolização da força física", a "estabilidade dos órgãos centrais da sociedade" e a "crescente divisão entre vida pública e vida privada, transformando a estrutura da personalidade" (ELIAS, 1993, p. 196-197).

O conjunto desses elementos faz com que seja implementado, desde a mais tenra infância, o autocontrole emocional como modo de organização e regulação das condutas públicas dos indivíduos, transformando-os em elementos basilares da ideia eliasiana de processos de civilização. Conforme sintetiza Gebara, os processos de civilização fundam-se na existência de processos não planejados, nos quais ocorrem alterações tanto nos controles externos (controles invisíveis decorrentes das relações sociais existentes no interior de cada sociedade) quanto nos controles da conduta individual (autocontrole), caminhando, na imensa maioria das vezes, na direção de um maior nível de autocontrole na regulação dos comportamentos individuais. Em decorrência dessa internalização e desse, cada vez maior, controle das emoções, sentimentos como vergonha, culpa, asco e gentileza conduziram os indivíduos à um padrão de conduta pautado por um maior refinamento e polidez (GEBARA, 2009, p. 29).

Nesse sentido, consideramos que no âmbito da abordagem analítica proposta por Elias para a análise dos processos civilizatórios as sociedades ocidentais europeias, e para os limites que propusemos abordar neste texto, o autocontrole assume grande importância. Especialmente, considerando-se que está intimamente relacionado ao aprendizado de normas e regras que regulam as condutas individuais tanto quanto regulam as relações (ou condutas) sociais.

Articulando essas proposições eliasianas, que destacamos acima, aos artigos nos quais são abordados os conceitos de civismo e de moral na Revista de Educação, podemos problematizar a função que esse periódico ocupou, como meio de divulgação de conteúdos considerados adequados e necessários para a formação docente.

Com o propósito de fazer circular as ideias mais modernas a respeito da educação escolarizada, bem como de fornecer informações a respeito dos princípios educacionais que 
pautariam as atividades dos futuros professores, os artigos publicados na Revista de Educação tiveram papel importante à medida que instruíam as normalistas sobre os saberes necessários para formar futuros cidadãos civilizados e capazes de contribuir para a formação e consolidação da nação brasileira.

Buscando superar os considerados atrasos do regime monárquico, as propostas republicanas de formação de uma nação esclarecida e moderna tinham a escola como o lócus no qual se garantiria a construção dessa nação pretendida. A nova civilidade, que se formaria a partir da escola, funcionaria como meio de cultivar e expandir a conduta social que se buscava para a construção da nova nação brasileira, agora republicana.

A nosso ver, com a Proclamação da República, em 1889, são incentivadas todas as formas de circulação das ideias republicanas e, portanto, contrárias ao regime monárquico, latentes na intelectualidade brasileira naquele momento histórico. Esse marco divisor (a Proclamação da República) permitiu um novo direcionamento para a função que a escola poderia exercer na formação do Estado brasileiro, que se considerava moderno. Com a República, o objetivo principal da educação passou a ser o de permitir a (e de ajudar na) construção de uma identidade brasileira de escola, de alunos e de futuros indivíduos para a sociedade. A partir da escola seria formado o cidadão civilizado e com uma conduta social e moralmente adequada aos anseios republicanos. Aos professores, portanto, caberia o domínio de técnicas e saberes especializados a partir dos quais seria possível formar esses indivíduos civilizados para uma sociedade republicana.

Observamos, portanto, que a civilidade requisitada para a formação das crianças passou a ser, juntamente com o ensino das primeiras letras, a pedra de toque do ensino modelarmente republicano. Nesse sentido, e de acordo com Lourenço e Razzini (2010, p.511, grifos dos autores):

Após a Proclamação da República, as representações da pátria presentes no currículo da escola elementar, ainda que ficassem mais visíveis na introdução das aulas de Educação Cívica, que visavam despertar nos alunos uma ideia nacional, e nos estudos das Constituições federal e estadual, alargaram-se também pelos conteúdos das matérias que formavam o tripé da identidade nacional (Língua Materna, Geografia e História). Tal influência alcançaria ainda as aulas de Música e as então chamadas festas escolares, solenidades públicas reservadas à celebração das datas nacionais (redefinidas para legitimar o novo regime), seja com a entoação de vários hinos, seja depois, a partir de 1906, com o hasteamento da bandeira brasileira. 
Além disso, outros aspectos que se destacam são a presença dos imigrantes e a concomitante formação, desenvolvimento e urbanização das cidades pelo Estado de São Paulo, especialmente nas primeiras décadas do século XX. Tendo se destinado à cafeicultura ou às fábricas, os imigrantes que vieram para São Paulo representavam certo perigo para a constituição da nação brasileira republicana. Visando à integração do imigrante e à formação de seus filhos para a pátria que os acolhia, a escolarização foi considerada o principal elemento capaz de evitar a perpetuação de valores trazidos pelos imigrantes, assim como de ensinar o idioma português, a história e a geografia brasileiras e, com isso, civilizar e moralizar os indivíduos.

Concomitantemente a escolarização dos imigrantes (e, principalmente, de seus filhos), há que se considerar o desenvolvimento urbano das cidades paulistas, acompanhando a expansão da cultura cafeeira por boa parte do Estado, e a progressiva formação de cidades e pequenas vilas próximas às ferrovias que eram utilizadas para o escoamento da produção do café. Com essa nova configuração social (no sentido que Elias utiliza esse conceito), as famílias, que antes viviam mais isoladas em suas propriedades, passaram a ter uma convivência social mais próxima com outras famílias.

Como conseqüência direta disso, essa nova configuração social propiciou maior controle das atitudes e condutas sociais, bem como a necessidade de um maior nível de autocontrole dos (e nos) indivíduos que compunham essas configurações sociais. Assim, podemos verificar que ocorreram alterações nos padrões de condutas sociais e individuais, modificados em razão das novas estruturas políticas, econômicas, culturais e educacionais, as quais, progressivamente, passaram a regular a sociedade paulista daquele momento histórico.

A partir da análise dos conteúdos de moral e civismo publicados na Revista de Educação (1921-1923), constatamos que no momento em que uma nova disposição social se organizava, em decorrência da instauração do regime republicano - e para isso, consideramos especialmente o caso do Estado de São Paulo -, e se buscava a formação dos futuros cidadãos da pátria a partir da educação das crianças, a escola passou a ser considerada o templo de civilização (SOUZA, 1998) que agregaria os elementos capazes de construir o novo indivíduo para essa nova nação. Nesse sentido, a divulgação dos valores 
morais e de civismo, considerados necessários para formar o professor, responsável direto pela educação do futuro cidadão para a pátria, assumiu significativa importância.

\section{Considerações finais}

Neste texto, apresentamos e problematizamos os conteúdos de moral e civismo divulgados nos artigos da Revista de Educação, periódico da Escola Normal de Piracicaba, publicado entre 1921 e 1923. Para a nossa análise, utilizamos aspectos da teoria dos processos de civilização, proposta pelo sociólogo alemão Norbert Elias, nas primeiras décadas do século XX. Dentro dessa teoria, dirigimos nosso foco à questão do controle das emoções no nível individual (autocontrole) e nas relações sociais (controle social). Elias questiona e problematiza o despertar dos sentimentos e atitudes que formam o padrão de comportamento de uma determinada época em uma determinada sociedade (configuração social), o qual, para esse autor, baliza as atitudes dos indivíduos, nas quais estão incorporadas as pressões externas advindas do ambiente social, o chamado controle social.

Consideramos que a abordagem que demos à análise do periódico explorou apenas alguns aspectos da teoria eliasiana, bem como não esgotou as inúmeras possibilidades de pensar a Revista de Educação, como um instrumento de difusão e circulação de uma dada cultura pedagógica presente naquele momento histórico. O que pretendemos, antes de esgotar as possibilidades de reflexão que a Revista de Educação pode propiciar, foi apresentar uma faceta analítica, tendo por base a abordagem eliasiana dos processos de civilização, e ensaiar uma análise do conteúdo veiculado nesse periódico, pensando no desenho de cidadão e de suas condutas sociais que vinham sendo requisitadas pelos anseios republicanos, assim como as intervenções efetuadas por meio da escola para a consecução desse ideal de cidadão.

Por fim, ressaltamos a importância da Revista de Educação como veículo de divulgação e discussão dos saberes educacionais e políticos daquele momento (principalmente pela divulgação das ideias nacionalistas republicanas), bem como a utilização de periódicos educacionais podem auxiliar como fontes de pesquisa sobre a educação brasileira e a necessidade de conhecer novas abordagens teóricas (como, por exemplo, as teorias propostas por Elias), que nos permitiu problematizar um momento 
histórico no qual se construiu a ideia de escola, cujo modelo está presente em nossa sociedade até os dias atuais.

\section{Referências}

ANDRADE, T. C. Do ensino de História. Revista de Educação, Piracicaba, v. 1, n. 1, p. 46-48, mai. 1921.

BITTENCOURT, C. Livro didático e saber escolar (1810-1910). Belo Horizonte: Autêntica, 2008.

BRANDÃO, C. F. Os processos de civilização e o controle das emoções. Bauru: Edusc, 2007.

BRASIL, D. O civismo pelo ensino de história. Revista de Educação, Piracicaba, v. 1, n. 1, p. 23-26, mai. 1921.

CARVALHO, M. M. C. Sampaio Dória. Recife: Fundação Nabuco, Ed. Massangana, 2010. Também disponível em: <http://www.dominiopublico.gov.br/pesquisa/DetalheObraForm. do?select_action=\&co_obra=205219>. Acesso em: 29 de ago. de 2012.

DE LUCA, T. R. A Revista do Brasil: um diagnóstico para a (N)ação. São Paulo: Ed. UNESP, 1999.

ELIAS, N. O processo civilizador: uma história dos costumes. Trad.: Ruy Jungmann. 2ed. Rio de Janeiro: Jorge Zahar, 1994. v. 1.

ELIAS, N. O processo civilizador: formação do Estado e civilização. Trad.: Ruy Jungmann. 2ed. Rio de Janeiro: Jorge Zahar, 1993. v. 2.

GEBARA, A. Civilização e descivilização na América Latina: o caso brasileiro. In: GOETTERT, J. D; SARAT, M. (Orgs.). Tempos e espaços civilizadores: diálogos com Norbert Elias. Dourados, MS: Ed. da UFGD, 2009. p. 13-32.

HILSDORF, M. L. S. Lourenço Filho em Piracicaba. In: SOUZA, C. P. (Org.). História da educação: processos, práticas e saberes. São Paulo: Escrituras, 1998. p. 95-112.

LOURENÇO, E; RAZZINI, M. P. G. Leitura e formação do cidadão republicano na escola elementar paulista. In: ODALIA, N; CALDEIRA, J. R. C. (Orgs.). História do estado de São Paulo: a formação da unidade paulista. São Paulo: Ed. UNESP, 2010. (v.2 - República).

MELLO, P. 7 de setembro de 1922. Revista de Educação, Piracicaba, v. 2, n. 2, p. 111-115, out. 1922.

MENNUCCI, S. Um jubileu. Revista de Educação, Piracicaba, v. 2, n. 1, p. 21-29, mai. 1922. 
NAGLE, J. Educação e sociedade na Primeira República. São Paulo: EPU, 1974.

NERY, C. C. B. Em busca do elo perdido: a ação reformadora de Oscar Thompson. 2009. 382 f. Tese (Livre Docência em Educação) - Universidade Estadual Paulista, Faculdade de Filosofia e Ciências. Marília, 2009.

SILVA, J. Discurso. Revista de Educação, Piracicaba, v. 2, n. 3, p. 155-161, dez. 1922.

SOUZA, R. F. Templos de civilização: a implantação da escola primária graduada no estado de São Paulo (1890-1910). São Paulo: Ed. UNESP, 1998.

Enviado em Agosto/2012 Aprovado em Setembro/2013 